\title{
APRESENTAÇÃO DO FAST-TRACK DA ANPAD 2009
}

\author{
Eduardo Diniz \\ Editor chefe da RAE-revista de administração de empresas \\ eduardo.diniz@fgv.br \\ Jorge Ferreira da Silva \\ Presidente em exercício e diretor científico da ANPAD \\ pres@anpad.org.br \\ Tomás de Aquino Guimarães \\ Diretor de comunicação e publicações da ANPAD \\ dircompub@anpad.org.br
}

Durante o Encontro da Associação Nacional de PósGraduação e Pesquisa em Administração (EnANPAD) de 2009, realizado em São Paulo, a diretoria da ANPAD anunciou uma proposta tanto interessante quanto ambiciosa. A ideia seria selecionar dentre os 10\% melhores trabalhos apresentados no EnANPAD 2009, e enviá-los para alguns periódicos de alto impacto, visando incrementar o nível de publicação de artigos de qualidade e, ao mesmo tempo, agilizar a avaliação dos melhores trabalhos apresentados em eventos dessa Associação.

Em total apoio a essa iniciativa, que imediatamente ficou conhecida como "fast-track da ANPAD", a RAErevista de administração de empresas, assim como diversos outros periódicos da área, se prontificou a participar dentro das condições propostas, aceitando o desafio de garantir a publicação dos artigos envolvidos nesse processo ainda no ano seguinte ao do evento, ou seja, em 2010. Essa iniciativa propunha valorizar o envio de artigos para eventos científicos, e passa a ser consagrada como a primeira etapa do ciclo de vida de um artigo acadêmico.

Não é a primeira vez que a RAE desenvolve uma parceria de publicação com a ANPAD. Em 1984, na edição $\mathrm{n}^{\circ} 4$ (outubro-dezembro) de seu volume 24 , a RAE publicou os anais da VII Reunião Nacional da ANPAD, ocorrida na Universidade Federal da Paraíba, em 1983. Nessa edição, o prof. Carlos Osmar Bertero, então diretor da FGV-EAESP, anunciava que a publicação dos anais tinha o objetivo de "atender a uma necessidade da área de Administração, que é a de registrar experiências e fazer circular informações". O prof. Roberto Costa Fachin, então presidente da ANPAD, em sua apresentação ressaltava que a editoração daqueles anais se apoiava na "experiência editorial da Revista de Administração de Empresas" para "colocar à disposição o acervo de pesquisas e ensaios divulgados anualmente nos encontros 
da ANPAD, como um retrato de parcela substancial dos trabalhos acadêmicos realizados pelos docentes e pesquisadores integrados aos programas de pós-graduação em administração".

Aquela edição foi organizada segundo a estrutura reformulada da ANPAD, com 30 artigos divididos em seis temas, cada qual com uma apresentação de seu então coordenador: Gestão Tecnológica (Gileno Fernandes Marcelino), Gestão e Participação (Roberto Venosa), Administração Pública (Paulo Roberto Motta), Responsabilidade Social da Empresa (Luiz Antonio Antunes Teixeira), Pequena e Média Empresa (Henrique Rattner) e Pesquisa em Administração (Clóvis L. Machado-da-Silva). Essa edição contou com artigos de Maria Tereza L. Fleury, Ruy A. S. Leme, José Carlos G. Durand, Carlos O. Bertero, Ernesto Lima Gonçalves, Tânia Fischer, entre outros importantes nomes da pesquisa em Administração no Brasil.

Desde então, a pesquisa em Administração no país cresceu muito em número de programas, alunos, professores, e isso se refletiu no aumento significativo da produção acadêmica na área. A ANPAD atualmente organiza um evento científico geral, o EnANPAD, com 11 divisões acadêmicas, oito das quais possuem seus próprios encontros específicos. Apenas no EnANPAD, mais de 1.000 artigos são apresentados anualmente. E essa enorme produção ainda carece de espaço de divulgação.

Em fins de outubro de 2009, a RAE (com a RAEeletrônica) recebeu uma lista de artigos sugerida pela diretoria da ANPAD. Essa lista procurava manter uma coerência entre a linha editorial do periódico e os temas dos trabalhos. Além disso, buscou-se evitar a indicação de mais de um artigo de um mesmo autor para um mesmo periódico e de artigos cujo autor fosse editor do próprio periódico.

A partir da aceitação, pela editoria da RAE e RAEeletrônica, da lista de artigos enviada, a diretoria da ANPAD entrou em contato com os autores convidando-os a submeterem seus respectivos artigos segundo as normas de submissão de cada periódico que aceitou participar do processo. Após a submissão dos artigos, eles foram identificados como parte do conjunto dos melhores trabalhos do EnANPAD 2009, portanto, a ser avaliado no modelo fast-track.

De uma primeira lista com oito artigos, um foi rejeitado por se tratar de um caso de ensino, portanto fora do formato dos artigos publicados pela RAE e RAEeletrônica, e outro não chegou a ser submetido pelos autores. Diante desse quadro e avaliando que a $R A E$ e RAE-eletrônica teriam condições de aceitar mais artigos, outros dois artigos, avaliados entre os $10 \%$ melhores trabalhos do Encontro de Ensino e Pesquisa em Administração e Contabilidade (EnEPQ) e do Encontro de Gestão de Pessoas e Relações de Trabalho (EnGPR), foram sugeridos para completar a lista.

Até o início de fevereiro, três dos oito artigos que estavam em processo de avaliação foram rejeitados pelos editores científicos por ainda não estarem em condições de publicação em periódicos de alto nível como a RAE e RAE-eletrônica. Os outros cinco artigos continuaram em processo de avaliação, tendo sido apreciados por meio do método double-blind review. Após as sugestões de melhorias dos avaliadores (dois para cada artigo) e depois de algumas rodadas de aperfeiçoamento envolvendo trocas entre os autores e editores científicos evidentemente mediadas pela equipe de redação e sem quebrar o sigilo entre autor-avaliador-editor científico esses cinco artigos estão agora disponíveis para os leitores e a comunidade de Administração (por decisão editorial, os cinco artigos foram publicados em conjunto apenas na RAE, não indo nenhum deles para a RAE-eletrônica).

Para esses cinco artigos, o tempo médio do processo de avaliação ficou em 201 dias (contados entre data de submissão pelos autores e a data de aprovação final pelos editores), cumprindo-se a promessa de realmente se fazer um fast-track, e sem que se tenha criado nenhum privilégio especial. Ou seja, o compromisso de publicar os artigos dentro do prazo de um ano não se deu à custa de nenhum privilégio para os artigos do fast-track, em detrimento dos artigos submetidos regularmente ao processo de avaliação da RAE.

É importante mencionar o envolvimento em todo esse processo de 24 autores de 11 instituições localizadas em oito estados de três regiões do país. Contamos ainda com o árduo e também profícuo trabalho de três editores científicos, todos coordenadores de divisão da ANPAD, e 10 avaliadores oriundos de oito instituições de ensino e pesquisa em Administração, distribuídas por cinco estados e três regiões.

O resultado de todo esse empenho está nesta edição da $R A E$, na forma de dois trabalhos empíricos e três ensaios teóricos, representando o que há de melhor na produção acadêmica na área de Administração no Brasil. Dado o sucesso da iniciativa neste ano, a diretoria da ANPAD e a RAE querem repetir a dose em 2011, com artigos apresentados em eventos dessa associação em 2010 , e continuar a apresentar artigos interessantes e inovadores como os publicados a seguir. 